ojs.uv.es/index.php/qdfed

Rebut: 30.04.202I. Acceptat: 27.09.202I

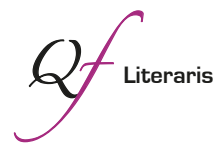

Per a citar aquest article: Álvarez, Ana Belén. 202I. “¿Víctimas o verdugos? El perfil de los perpetradores en La paloma de Ravensbrück". Quaderns de Filologia: Estudis Literaris XXVI: I29-I46.

doi: $10.7203 /$ qdfed.26.22103

\title{
¿Víctimas o verdugos? El perfil de los perpetradores en La paloma de Ravensbrück
}

Victims or executioners? The perpetrators' profile in La Paloma de Ravensbrück

\author{
Ana Belén Álvarez \\ The University of Alabama \\ aalvarezvivo@ua.edu
}

Resumen: La historia de Neus Català, recogida en La paloma de Ravensbrück (2019) de Carme Martí, es el hilo conductor de este artículo. El objetivo es demostrar que durante la Guerra Civil española y la Segunda Guerra Mundial hubo perpetradores no normativos y, a su vez, personas no presentadas como perpetradores que sí cumplieron con las características de estos. Por un lado, busco un acercamiento al concepto de perpetrador mediante los indicios que se encuentran en la obra de Martí teniendo en cuenta no solo a policías, guardias o soldados, sino también a los testigos y las propias presas. Y, por otro lado, mediante la teoría de la disciplina y el castigo de Foucault, analizo las acciones llevadas a cabo por las diferentes figuras como parte del ejercicio de definición del concepto vehicular.

Palabras clave: perpetrador; Guerra Civil española; Segunda Guerra Mundial; campo de concentración; perfil criminal.

Abstract: The story of Neus Català, collected in Carme Martís novel La Paloma de Ravensbrück
(20I9), is the thread of this article. The objective is to demonstrate that during the Spanish
Civil War and World War II there were non-normative perpetrators, as well as people not pre-
sented as perpetrators who did meet their characteristics. On the one hand, I seek an approach
to the concept of the perpetrator through the indications found in Martís work, considering not
only the police, guards, or soldiers, but also the witnesses and the female prisoners themselves.
And, on the other hand, through Foucault's theory of discipline and punishment, I analyze the
actions carried out by the different figures as part of the definition exercise of the vehicular
concept. Keywords: perpetrator; Spanish Civil War; World War II; concentration camp; criminal profile. 


\section{Introducción}

Sigmund Freud, en su libro Group Psychology and the Analysis of the Ego (I922), define las masas como entidades temporales, unidas por elementos heterogéneos y con elevados sentimientos de poder y seguridad debido a la retroalimentación entre sus miembros. Freud declara que, en general, las masas son impulsivas, irritables y suelen estar controladas por el inconsciente y su identificación con un líder; por lo tanto, son grupos de personas fácilmente maleables, sobre todo dentro de un contexto bélico. En este sentido, el fascismo italiano puede rastrearse hasta el siglo XIX, aunque es en la época contemporánea a la Primera Guerra Mundial (I9I4-I9I8) cuando se agrupan, en primer lugar, en el Fascio d'azione rivoluzionaria en I9I4, el cual ve el conflicto bélico como una oportunidad de desarrollo social y político y, en I9I9, en los Fasci italiani di combattimento, un movimiento marcado por el eclecticismo ideológico. No es, sin embargo, hasta tres años después de acabar la Gran Guerra, cuando Benito Mussolini fundó el Partido Nazionale Fascista, única formación política legal en Italia entre I925 y I943. En poco tiempo esta ideología incluyó el totalitarismo, el nacionalismo y la exaltación de la raza, y se diseminó por el continente europeo. De este modo, para I933 el nacionalsocialismo alemán, influido por la tradicional hostilidad alemana hacia los judíos y por el fascismo italiano, ya se encontraba gobernando el país germano con políticas antisemitas, auspiciadas por el racismo científico y las teorías eugenésicas ${ }^{\mathrm{I}}$.

La retroalimentación de grupo que señala Freud fue, sin duda, una de las variables necesarias para que, durante la Segunda Guerra Mundial (I939I945), el fascismo alemán impusiera sus ideales en los territorios que dominaban. Con el objetivo de aterrorizar a los oponentes del régimen nazi, hacia I933, el socialismo nacional alemán levantó los primeros campos de concentración, técnicamente llamados campos iniciales, para albergar a opositores políticos en su mayoría. No fue hasta I939 cuando comenzó la persecución de judíos y ciudadanos de otras naciones a través de los primeros registros y detenciones. Más tarde, entre los años I942 y I945 se llevó a cabo la persecución masiva de judíos y se establecieron de manera organizada los campos de

\footnotetext{
I Para más información sobre la historia del fascismo italiano y la relación con la Alemania nazi ver el estudio de Robert O. Paxton, The Anatomy of Fascism (2005), el libro Italian Fascism: Its Origins and Development (2000) de Alexander De Grand y el libro Mussolini and Hitler: The Forging of the Fascist Alliance (20I8) de Christian Goeschel, en el que se alude al gran papel que desempeñó el líder italiano en las relaciones con Alemania.
} 
exterminio ${ }^{2}$. Muchos fueron condenados a trabajos forzados de manera perpetua bajo el lema "El trabajo te hace libre" (Arbeit macht frei), pero la realidad fue que la mayoría murieron exhaustos, de inanición, como consecuencia de los experimentos médicos e incluso por suicidio. Tal como predijo Raphael Lemkin en "Genocide", estudio pionero sobre el genocidio, esta violencia de masas se basó en un proceso de destrucción de la identidad de la víctima para imponer la propia del grupo opresor (I946: 228).

La violencia ejercida dentro de los campos de concentración era, no obstante, entendida por los nazis como su propio modo de ejercer el poder: una nueva forma de castigar de una manera, aparentemente, más humana. Esta es, precisamente, la definición que da Michel Foucault sobre la disciplina en su libro, Discipline \& Punish: the birth of the prison (I995), en el que explica que este es un tipo de poder mediante el cual controlar los cuerpos de los hombres, entendidos como unidades disociables. Foucault detalla, además, que la coerción ininterrumpida y sutil sobre todas las partes de un cuerpo es la que logra que este se vuelva más útil y, por lo tanto, más obediente (I995: I36-I37).

Pese a la situación europea descrita, muchos españoles se vieron obligados a exiliarse tras la victoria del bando sublevado que puso fin a la Guerra Civil el I de abril de I939 e inició la dictadura de Francisco Franco hasta I975. Neus Català (I9I5-20I9) fue una de las muchas mujeres comunistas convencidas que, junto a ciento ochenta y dos niños de una colonia de refugiados donde ejercía de enfermera, se anticipó a la citada victoria tras la caída de Barcelona en enero de I939 y huyó a Francia. En I943, los nazis irrumpieron de madrugada en la granja donde vivía junto a su marido Albert, que servía de centro de operaciones y refugio de los maquis ${ }^{3}$, dando comienzo a una pesadilla que duraría dos años. Su testimonio, recogido por Carme Martí en La paloma de Ravensbrück4 (20I9), narra los horrores que vivió estando presa, primero en Francia, y después condenada a trabajo perpetuo en un campo de concentración alemán.

\footnotetext{
${ }^{2}$ Para conocer en profundidad las diferentes etapas de los campos de concentración y sus presos, consultar The United States Holocaust Memorial Museum Encyclopedia of Camps and Ghettos, 1933-1945 (2009) de Geoffrey P. Megargee y Elie Wiesel; concretamente el capítulo "Early Camps, Youth Camps, and Concentration Camps and Subcamps under the SS-Business Administration Main Office".

${ }^{3}$ Se denomina maquis tanto a la guerrilla de resistencia antifranquista durante la posguerra civil española como a la resistencia francesa contra la ocupación alemana durante la Segunda Guerra Mundial, según la Real Academia Española.

${ }^{4}$ Este libro se publicó inicialmente en el 2012 bajo el título Cenizas en el cielo.
} 
La obra de Martí nos servirá de hilo conductor para analizar las contrafiguras narrativas que fueron apareciendo durante el exilio de la protagonista. El objetivo de este artículo será demostrar que hubo perpetradores no normativos y, a su vez, personas no presentadas como perpetradores que sí cumplieron con algunas de las características que se les pueden atribuir a estos. De este modo, dividiré mi análisis en dos partes. Por un lado, definiré el concepto de perpetrador mediante los indicios que se encuentran en la obra de Martí. Tal como indica Saira Mohamed en su artículo "Of Monster and Men: Perpetrator Trauma and Mass Atrocity" (2015), analizar esta figura no significa simpatizar con ella ni justificar sus actos, sino comprender qué le impulsó a cometer un crimen y analizar el sufrimiento que este podía acarrear (2015: I2I2). No solo me limitaré a describir a policías, guardias o soldados, también buscaré señales de perpetración dentro de otros grupos como los testigos o las propias víctimas. Por otro lado, mediante la teoría de la disciplina y el castigo de Foucault, investigaré las acciones llevadas a cabo por las diferentes figuras de la novela analizada como parte del ejercicio de definición del concepto vehicular. Pese a que muchos de los ejemplos analizados en este ensayo pertenecen al Holocausto, tras el cambio de siglo, tal como indican los investigadores Aleida Assmann y Sebastian Conrad en su libro Memory in a Global Age, este acontecimiento está tan universalizado que se puede considerar un fenómeno transnacional (2010: I4).

\section{Una aproximación al concepto de perpetrador}

Entender la razón por la que una persona participa en la ejecución de crímenes de masas es una tarea compleja que puede comenzar por comprender las características que hacen diferente a quien decide cometer un acto violento y al que no. En el libro Nuestra personalidad: en qué y por qué somos diferentes (2004), Manuel de Juan Espinosa y Luis Francisco García Rodríguez establecen que las diferencias en la personalidad se deben a la variedad genética y a los diferentes ambientes a los que un individuo se ha adaptado a lo largo de su vida. A partir de esta base y definiendo los factores de riesgo, David Farrington, en "Childhood Origins of Antisocial Behavior", establece una serie de indicadores de comportamiento antisocial que pueden llevar a una persona a consumar actos criminales (2005: 182). En el contexto que nos compete, según el estudio de Guenter Lewy, recogido en Perpetrators: The World of the Holocaust Killers, lejos de los estereotipos que podamos imaginar como aso- 
ciados a algunos trabajos, ideologías políticas o personalidades que coincidan con la figura del perpetrador normativo, no existe un perfil criminológico típico de los perpetradores encargados de los campos de concentración. Por el contrario, Lewy propone un amplio abanico de sujetos con diferentes motivaciones: tipos sádicos movidos por sus instintos más básicos, nazis comprometidos con su ideología, oportunistas, hombres comunes que seguían órdenes y, también, aquellos que eludían las más desagradables, como matar (Lewy, 20I7: 45).

Además de la dificultad que conlleva categorizar a estas personas, debe también tenerse en cuenta la denominada "zona gris", término acuñado por Primo Levi en el libro The Drowned and the Saved (1986: 25) y que hace referencia a la moral ambigua que invadió los campos de concentración. Por lo tanto, a continuación, me aproximaré a la definición de perpetrador desde tres perspectivas distintas: los normativos, los no normativos y los testigos; esta clasificación pretende formular tres perfiles basados en sus acciones o inacciones y en la motivación detrás de estas.

\subsection{Los perpetradores normativos}

Neus Català en muy pocas ocasiones juzga a los agresores españoles, franceses o alemanes con los que se ha cruzado, más bien trata de centrarse en describir lo vivido. Algunos de los comentarios que la protagonista hace sobre las SS, las escuadras de protección al servicio de Hitler, son que tienen un "aire presuntuoso e insolente" (Martí, 20I2: 23) y son "miserables y crueles" (Martí, 20I2: 122). Además, el día que se ve forzada al exilio con los niños del refugio explica que "la aviación italiana y la alemana bombardeaban lo que para ellos representaba un blanco fácil, una procesión de gente que avanzaba poco a poco" (Martí, 20I2: 75), haciendo ver al lector la facilidad que tienen estos individuos para llevar a cabo ejecuciones masivas.

Lejos de la subjetividad de la novela, traspasar la barrera de lo que hace un acto de perpetración o no es algo que puede suceder fácilmente y provenir también de las personas e instituciones que sancionan esas mismas acciones. El derecho a castigar, basado en la expresión latina merum imperium o el poder de utilizar la fuerza pública para hacer cumplir los preceptos legales, es un modo que tienen los poderes de un país de exigir una retribución a los perpetradores. En este sentido, explica Foucault que el hecho de que el crimen y el castigo converjan de una forma atroz es consecuencia de los mecanismos de 
poder (I995: 57). Por este motivo, en los campos de concentración la retribución que mayoritariamente se reclamaba era el pago de la identidad de los presos; ser judío, comunista, anarquista, homosexual, discapacitado, republicano español, como Neus Català, o de cualquier otro colectivo considerado inferior por los nazis era motivo suficiente para la condena.

Las acciones de los perpetradores dependen del grupo social y/o político al que pertenecen y que define el objetivo común. Joseph Gregory DeLeeuw y William Alex Pridemore han probado que, según la motivación de estas organizaciones, los perpetradores pueden ser de derechas, de izquierdas, separatistas o con motivaciones muy concretas (2018: 27). Pese a que sus investigaciones están enfocadas en el terrorismo, la definición que dan de este último tipo encaja perfectamente con la situación vivida durante la Segunda Guerra Mundial, pues estas contrafiguras normativas actuaban bajo el ideario nacionalsocialista. Es decir, el objetivo del terrorismo es imponer sus ideas políticas mediante actos que infunden terror y, tal como concluye el estudio de Jon Juaristi Linacero "Holocausto y terrorismo": "el Holocausto, con todo, sigue siendo para el terrorismo integrista y sus auspiciadores el modelo más logrado de aniquilación colectiva del enemigo inasimilable" (2009: 66). Además, este hecho conecta con la idea de Christopher Powell, desarrollada en el libro Barbaric Civilization (20II), según la cual los perpetradores crean una red identitaria en la que apoyarse para cumplir su propósito. En el caso del nacionalsocialismo, el origen de estas redes de afinidad ideológica se encuentra, según indica Daniel Jonah Goldhagen, en la política antijudía alemana proveniente del antisemitismo eliminacionista (I997: 375). Paralelamente, la situación dominante de las tropas alemanas diseminadas por Europa durante la Segunda Guerra Mundial propició las circunstancias perfectas para llevar a cabo el exterminio.

Goldhagen, en su libro Hitler's Willing Executers: Ordinary Germans and the Holocaust (1997), trata de comprender las diferentes motivaciones de estas personas a través de tres cuestiones clave: ¿tuvieron voluntad de asesinar?, ¿qué les motivó a matar y torturar? y ¿cómo se engendró dicha motivación? (I997: 375). Para ello, comienza por desmontar, una a una, las cinco justificaciones socialmente más aceptadas acerca de las acciones de estas personas. En efecto, Goldhagen argumenta que existen evidencias de que ningún alemán fue asesinado o encarcelado por negarse a acabar con los judíos, no se puede aludir a una supuesta tendencia innata de los alemanes a obedecer, no recibieron presiones por parte de sus compañeros o superiores, tampoco iban 
a conseguir ascensos ni incentivos y, además, entendían perfectamente las consecuencias de sus acciones (I997: 38I-385).

Sobre los dos primeros argumentos, cabe mencionar un episodio que narra Lewy en su libro. Él esclarece que el I2 de diciembre de I94I, Heinrich Himmler emitió una orden en la que se reconocía la difícil tarea que tenían los destacamentos encargados de asesinar en los campos de concentración. Por este motivo, explica que si alguno de los oficiales se sentía incapaz de llevar a cabo su cometido podría ser relevado de su cargo y destinado a otra unidad. Pese a que esta directiva estaba orientada a la llamada Solución Final, Lewy indica que, posiblemente, hubo otras directrices similares durante la Segunda Guerra Mundial (20I7: 75). Por lo tanto, concluye Goldhagen, que la acción de estos hombres y mujeres fue motivada por una fuerte ideología que se maquinó desde las más altas esferas alemanas y se apoderó de las vidas de su gente. La siguiente cita, extraída del libro de Goldhagen y originalmente publicada el 2 de abril de I943 en el periódico alemán Deutscher Wochendienst, recoge a la perfección la esencia antisemita que se inoculó en la sociedad alemana y la raíz de la motivación que desencadena su conducta:

In the case of the Jews there are not merely a few criminals (as in every other people), but all of Jewry rose from criminal roots, and in its very nature it is criminal. The Jews are no people like other people, but a pseudo-people welded together by hereditary criminality. [...] The annihilation of Jewry is no loss to humanity, but just as useful as capital punishment or protective custody against other criminals (1997: 394).

En efecto, al poco de llegar a Ravensbrück, Neus Català reflexiona: "Las SS, con las piernas abiertas, cargadas con escopetas y látigos, ¿no tenían ni una chispa de humanidad? A los prisioneros se los alimenta, ¿no? A los animales se los alimenta, ¿no?” (2019: I36) y nos hace comprender que allí se siente completamente humillada, al ser tratada peor que un animal.

\subsection{Los perpetradores no normativos}

El hecho de que investigadores como Goldhagen o Lewy evidencien casos de SS que se negaron a cumplir órdenes de ejecución implica que hubo perpetradores considerados normativos por su trabajo pero que, en realidad, no cumplieron con el modelo arquetípico. Tal como detalla Mohamed, el mal innato no existe, pero sí las malas decisiones en momentos en los que la 
ideología y el odio se apoderan de uno (20I5: I2IO). Una de las escenas más conmovedoras dentro de la novela de Neus Català ocurre cuando el tren, en el que se encuentra rodeada de cientos de mujeres y custodiada por las SS, para en la estación francesa de Campiègne. Allí Neus observa unos brazos agitándose, saliendo de las ventanillas de otro tren de transporte de ganado, por lo que le entra curiosidad y decide sacar la cabeza también por la ventana. En ese instante su mirada se cruza con la de Albert y explica que lo peor no fue saber que su tren también se dirigía a un campo de concentración, sino percibir la misma desesperación que ella estaba sufriendo. Esta conexión le provoca tal histeria que le lleva a pegar patadas y gritar. El SS que vigila el vagón respeta el espacio de su dolor y, cuando ella misma deja de ver el tren en el que va Albert y se aparta de la ventana, él la cierra y Neus se da cuenta de que al SS le están cayendo lágrimas de los ojos (Martí, 20I2: 56). Lo sorprendente de este momento es ver a una persona que, por su ideología y función, es etiquetada de perpetrador y, sin embargo, se aleja de la normatividad al mostrar estos sentimientos.

Algo similar sucede con Edmond, el comandante encargado del campo de concentración de Flossenbürg. Neus narra sorprendida que, nada más llegar a ese campo, el comandante les da una buena sopa, ropa nueva y deja descansar a las presas; todo lo contrario a lo que estaban acostumbradas. Elsa, la encargada del bloque en el que duerme Neus, les aclara que el mismo Edmond fue "prisionero de guerra durante la Primera Guerra Mundial" (Martí, 20I2: I64) y continúa diciendo que su propia experiencia le llevó a mejorar la situación de las mujeres que tenía a su cargo. Por lo tanto, este comandante está en la posición normativa de perpetrador y, sin embargo, no actúa siempre como tal, aunque sí lo intenta. Expresa la protagonista que "no es ningún sádico, pero tampoco es buena persona" (20I2: I78) y tiene muchos cambios de humor, seguramente como consecuencia de intentar cumplir con las expectativas que se tenía de las SS. Pero evidentemente los buenos actos que Edmond tiene hacia las presas hacen que lo destituyan; "No es lo bastante malo para llevar un campo de la categoría de Flossenbürg”, comenta Neus (Martí, 20I2: I78) y añade que, para este tipo de trabajo, escogen "a la chusma" (Martí, 20I2: I78), refiriéndose a una SS que pega sin motivo intentando clavarles su anillo en los ojos.

Dentro de los campos de concentración existen dos cargos que ejercen funciones de guardián a cambio de beneficios. Las kapo, responsables del campo en general, y las blokova, encargadas de vigilar sus bloques, colaboraban con las SS sin perder su consideración de presas y, por lo tanto, de víctimas. El 
objetivo de las SS era que se creara una especie de primera línea de delatoras bajo la que las demás presas mantuvieran un estado de alerta permanente, ya que podían ser delatadas en cualquier momento. Siguiendo con el acontecimiento anteriormente relatado en Flossenbürg, la protagonista cuenta que, pocos días después de destituir a Edmond, las kapo y otras supervisoras se abalanzaron sobre ellas y les pegaron (Martí, 20I2: I82). Es interesante destacar que las kapo son quienes llevan a cabo una acción infame contra sus propias compañeras y, además, el narrador utiliza el artículo femenino "la" para acompañar la palabra Aufseherinnen, que significa supervisor en alemán. Por lo tanto, este pasaje define dos nuevos tipos de perpetradores que no encajan con la iconografía inicial de esta figura: las mujeres y las presas.

\subsection{El papel de los testigos}

Los testigos merecen una mención aparte por su condición de ciudadanos de pleno derecho y, en un principio, no estar implicados en el conflicto. Dentro del campo de estudio de los perpetradores, el concepto de testigo puede tener diferentes acepciones y connotaciones según su grado de implicación. Por un lado, un espectador, o bystander es cualquier individuo "characterized by their moderate stance between the highly conforming perpetrators and the independently minded rescuers" (Baum, 2008: I53), es decir, son meros observadores pasivos. Y, por otro lado, un testigo, o witness, es aquel que ha presenciado unos hechos y ha formado parte de ellos a través de "procesos atencionales, perceptivos, del lenguaje y de pensamiento" para, posteriormente, construir su propio testimonio (Manzanero \& Álvarez, 20I5: 275). No obstante, la complejidad de estos conceptos testimoniales hace que esta dicotomía no sea suficiente y nuevos estudios, como el de Sibylle Schmidt, se cuestionen también los factores hermenéuticos y morales aparejados al perpetrador como testigo ${ }^{5}$. Es, precisamente, dentro de este último campo en el que encuadro este apartado sobre los perpetradores.

En este caso, como en los dos anteriores, no existe un perfil criminológico típico de los testigos, pero en la novela sí se encuentran situaciones en las que estas figuras realizan actos arquetípicos. Foucault explica que, durante

\footnotetext{
5 En su artículo "Perpetrators' Knowledge: What and How can We Learn from Perpetrator Testimony?” (20I7), publicado en el Journal of Perpetrator Research, Sibylle Schmidt explora la brecha teórico-conceptual existente entre witness, bystander y perpetrador.
} 
la Ilustración (I7I5-I789), la sociedad tenía el derecho a ser testigo de los castigos públicos y lo ejercían muy fervientemente. El carácter público de estos actos favorecía a ambas partes: por un lado, el pueblo se aseguraba de que la justicia cumplía las sentencias y, por otro lado, el monarca mostraba su poder (Foucault, I995: 6I). Parte de este derecho consistía en acompañar en procesión al condenado junto con los verdugos hasta el lugar de su ejecución. En ocasiones, las masas, ebrias del poder que les otorgaba este derecho, se volvían violentas contra el condenado, algo que el monarca percibía como una muestra de lealtad de ellos hacia su persona (I995: 59). En el contexto que nos compete, estas mismas situaciones vuelven a darse y Neus Català deja constancia de ello. Ella explica que, estando presa en la cárcel de Limoges (Francia), un día unos guardias la sacaron de la celda y la hicieron subir a un coche, "me obligaron a sacar la cabeza por la ventanilla y dieron vueltas y más vueltas por Limoges" (20I2: II7). Pese a que el objetivo del viaje era el traslado de Neus a la comisaría de policía para someterla a un segundo interrogatorio mucho más severo, este acto puede interpretarse como las procesiones que describe Foucault. Los guardias buscaban un refuerzo de su poder por parte de la gente de Limoges y, aunque no se hace referencia a la reacción de estos, Neus sí incide en que "[los guardias] mostraban a su presa y querían que la gente me mirase" (20I2: II7).

Este tipo de perpetración difusa por parte de figuras no normativas se vuelve mucho más evidente en otros dos momentos de la narración. Neus decide, en enero de I939, que es el momento de exiliarse a Francia junto con los ciento ochenta y dos niños que están a su cargo en la colonia de refugiados. Ella cuenta cómo, tras días de caminar bajo los bombardeos constantes, el hambre y el frío, al llegar al pueblo francés de Voló los habitantes les insultaban a su paso y les tiraban mendrugos de pan, como si fueran animales (20I2: 78). Neus justifica, en cierto modo, esa escena cuando dice:

Los refugiados molestábamos, éramos un quebradero de cabeza que los franceses no sabían cómo solucionar, medio millón de quebraderos de cabeza que llegaban para refugiarse en su país. Enviaban a la gente a campos de refugiados como el de Argelès, que eran más que nada como campos de concentración (2012: 79).

Aunque Neus pueda demostrar cierta empatía con esta cita, lo cierto es que la bienvenida tan solo es un primer indicio de los actos que los habitantes del lugar acaban cometiendo. Los ciudadanos de a pie, los policías galos o los nazis, cualquiera puede apoderarse de la plasticidad que ofrece el concepto 
de perpetrador, es decir, cualquier persona puede, en un momento dado, cometer actos violentos. Del mismo modo, en otro momento, Neus explica de una manera muy fugaz otro episodio parecido. Describe que, estando en el campo de Ravensbrück, mientras vuelven de una larga jornada de trabajos forzados moviendo tierra, unos niños de apenas diez años les tiran piedras (20I2: I42). Este acto está cargado de simbolismo por dos motivos. En primer lugar, demuestra que las acciones de las autoridades alemanas para concienciar a la población de la necesidad de llevar a cabo las prácticas eugenésicas están dando resultado. Pese a no comprender quizás el alcance de sus actos, estos niños perpetúan el discurso nazi adaptándolo a sus recursos. Este es un ejemplo del resultado del tipo de discurso que se apoderó de las vidas de la sociedad alemana, tal como he mencionado en el apartado 2.I. Y, en segundo lugar, el efecto que tiene en estas presas el sentirse rechazadas por unas personas que deben ser neutrales, como es el caso de los menores, implica una magnificación del poder de los nazis.

\section{Las acciones que identifican a los perpetradores}

El primer campo de concentración se construyó en Dachau, Alemania, en I933 por orden directa de Himmler. A partir de ese momento, el poder de la potencia nazi fue aumentando exponencialmente y los destinatarios de los campos de concentración ya no fueron solo los prisioneros políticos. Lo mismo ocurrió en Francia, donde se internó a más de medio millón de españoles considerados extranjeros indeseables, y en la España franquista que encerró a republicanos, anarquistas y homosexuales en unos trescientos campos de concentración. Dentro de estos lugares, las normas y el control que se ejercen sobre los reclusos son más o menos similares, pero siempre se inclinan hacia la disciplina. De los cuatro modos de vigilancia y uso de las personas que define Foucault, analizaré, dentro del contexto de este artículo, los dos primeros, el arte de la distribución y el control de la actividad, y haré una mención especial a la tortura.

\subsection{El encierro}

La importancia del encierro radica en el principio de Foucault sobre el arte de la distribución como base para incrementar el poder sobre los reos. Este autor alega que, a través de cuatro técnicas interconectadas, se puede llegar a 
una ordenación funcional de los presos y dejar espacio para la individualidad de sus cuerpos. De este modo, aplicar la disciplina y el castigo determinado es mucho más simple. El objetivo de esta configuración es, por lo tanto, crear espacios arquitectónicos, funcionales y jerárquicos en los que poder proyectar la disciplina.

La primera de estas técnicas es la clausura y, junto a esta, la segunda es la división celular. En efecto, los campos de concentración son, por definición, lugares cerrados en los que se busca el aislamiento de los condenados del resto de la sociedad. En cuanto a la división celular, pese a hacer referencia al aislamiento individual, los campos se dividen en dos zonas: una para los presos, en la que se alinean los barracones y está rodeada por una valla de seguridad y torres de vigilancia, y otra donde se llevan a cabo las actividades administrativas y pueden vivir las SS (Cuervo, 20I7: 195). El propósito de estos dos procedimientos es el control de los reclusos, pues el hecho de que los guardias y funcionarios sepan en cada momento dónde se encuentra cada grupo de personas y que este se sepa vigilado evoca un control real y psicológico constante.

Neus Català estuvo en tres campos de concentración: el primero en Royallieu, Francia, después en el campo alemán de Ravensbrück y, finalmente, en el de Flossenbürg en la antigua Checoslovaquia. Cuando describe estos dos últimos utiliza conceptos como block, o "barracón" en español, calle, focos y torres de vigilancia. Su testimonio corrobora, por lo tanto, la idea de que estos lugares de detención estaban construidos según unos patrones concretos de maximización de la disciplina. De un modo más subjetivo, Neus describe su llegada a Ravensbrück con la siguiente cita: "La escena es tan espantosa que me cuesta pensar, pero soy plenamente consciente de que dejo el mundo y entro en otro lugar. Un no-mundo, un lugar que no está en el mundo y que se puede parecer al infierno, aunque tampoco es el infierno" (Martí, 20I2: I23). Gina Herrmann esclarece que Ravensbrück se construyó en I938 para, inicialmente, aislar y reformar a personas que presentaran algún comportamiento asocial, tales como alcohólicos o vagabundos. Sin embargo, acabó convirtiéndose en el mayor campo de concentración para mujeres de Alemania, albergando a mujeres de más de treinta nacionalidades diferentes (2012: 240).

La tercera técnica que menciona Foucault consiste en la funcionalidad de estos espacios, es decir, la distribución y aislamiento de los presos a través de espacios útiles. En el caso de Neus Català, ella fue condenada a trabajos forzados a la perpetuidad (Martí, 2012: 58). Además, para que rindiera mejor en el trabajo declara que, a los pocos días de llegar a Ravensbrück y haber pasado 
por un reconocimiento médico, les pusieron una inyección que las dejó "sin regla y estériles, preparadas para trabajar" (Martí, 20I2: I35). Los primeros trabajos que desempeña Neus sirven solamente para mantener a las mujeres ocupadas y desgastarlas física y mentalmente. Se encargan de mover montañas de tierra de un lado al otro (Martí, 20I2: I4I) y de drenar un lago (Martí, 20I2: I48, I54). No obstante, las SS perfeccionan este instrumento disciplinar y convierten el trabajo en producción, tal como refiere Foucault. En el campo de trabajo de Holleischen, adscrito a Flossenbürg, Neus trabaja en la fábrica Skoda produciendo balas antiaéreas durante doce horas seguidas sabiendo, además, que estas son utilizadas para atacar a los suyos (Martí, 20I2: I64).

Por último, la cuarta técnica es el rango que ocupan las personas privadas de su libertad dentro de este subsistema de organización social. De la novela de Carme Martí se desprende que, a todas las mujeres, al llegar a los campos y pasar un período de cuarentena, se les rapa la cabeza y se les da un uniforme de rayas azul y gris (2012: 130). Herrmann añade que el proceso de ingreso también consistía en desvestirlas, someterlas a una revisión ginecológica poco higiénica y revisarles los dientes y su masa muscular (2020: 240). De este modo, lo que se consigue es desprenderlas de su identidad y deshumanizarlas. Neus Català, por ejemplo, explica con rabia que pasó a ser la prisionera 27.534 y llevaba, además, un triángulo rojo invertido y una $\mathrm{F}$ que la identificaban como presa política francesa ya que, al casarse con Albert, de origen francés, adquirió dicha nacionalidad (Martí, 2012: 130).

\subsection{El control de la actividad}

Una vez que los prisioneros están ordenados bajo una primera línea de disciplina y poder, Foucault explica la segunda técnica de control basada en la actividad (I995: I49-I56). Si en la distribución se entendía el trabajo como la funcionalidad del espacio, aquí se relaciona con el impacto que este tiene sobre el cuerpo. En este sentido, el establecimiento de ritmos, la adjudicación de determinadas actividades y, sobre todo, la regularidad en la repetición de las rutinas son la base del control individual y, por lo tanto, de la disciplina y el poder.

Estando en el campo de Flossenbürg y después de que destituyeran al comandante Edmond, la nueva autoridad al frente de este lugar impone las siguientes normas: "Prohibido llevar cinturón, bolsillos y bolsas. [...] Prohibido peinarse. Prohibido reír. Prohibido cantar. Prohibido hablar en el comando" (Martí, 20I2: I8I). Herrmann explica que el objetivo de estos rituales diarios y prohibiciones es aterrorizar a las mujeres y romper sus identidades feme- 
ninas (2020: 238). De hecho, la propia Neus hace referencia a ello cuando menciona que recogerse el pelo en un pañuelo que les han dado "es el acto más humano de todo el día" (2012: 165).

En cuanto al tiempo que se dedica a dicha actividad, Foucault explica que la disciplina admite una economía del tiempo positiva, es decir, su objetivo es un aumento progresivo del tiempo que se dedica a esta. No se busca trabajar sin perder el tiempo, sino el agotamiento trabajando. Del testimonio de Neus se desprende esta misma esencia pues, salvo en la cárcel de Limoges, en la que no se le conoce ninguna actividad, en los dos campos de concentración en los que estuvo cuenta que se pasaba hasta doce horas seguidas realizando actividades de gran demanda física.

Otro modo de agotar los cuerpos para volverlos más dóciles es mediante el racionamiento de las comidas. Neus explica que, como represalia a una emboscada de los resistentes libres, los guardias de la cárcel de Limoges no les dejan salir al patio durante una semana y les llevan la sopa a intervalos cada vez más largos (Martí, 20I2: 23). El hambre es uno de los lamentos que más se repite a lo largo de la novela, y Neus explica que pasó hambre en todos y cada uno de los lugares en los que estuvo retenida. La cita que mejor describe el resultado de este modo de control es la siguiente:

Tener sed cada día, tener hambre cada día. Sentir la sed como un relámpago que te quema la garganta. Sentir el hambre como un agujero que te crece en el estómago y se extiende por las entrañas, y se hace cada vez mayor, cada vez más, y quiere devorarte. Hacer cola para una sopa que no es sopa y tener diarrea por la sopa que has anhelado (Martí, 20I2: I78).

A la falta de alimento se le une también la falta de descanso. Cuenta Neus que en Ravensbrück la sirena sonaba a las 3 de la madrugada y en Holleischen a las 4. Desde ese momento, y con tan solo un poco de líquido en el cuerpo, tenía que aguantar las largas jornadas de trabajo esclavo, las torturas y las humillaciones. Esta extenuación es el último punto que menciona Foucault dentro del control de la actividad. Una vez el individuo ya ha interiorizado estos mecanismos, entrega su cuerpo a la autoridad para su manipulación.

\subsection{Las torturas}

Llegados a este punto en el que el perpetrador tiene a sus víctimas bajo un estricto sistema de organización y vigilancia y controla su actividad perma- 
nentemente, el nivel de poder que se desprende es vasto. No obstante, no se debe perder de vista que el objetivo de las acciones descritas en los puntos anteriores es castigar, mas el nivel de poder de quienes las cometen llega a su punto álgido cuando el castigo se convierte en tortura. Según Foucault, para que esto ocurra, las acciones deben cumplir con tres criterios: producir cierto grado de dolor, tener la capacidad para su regulación y, por último, formar parte de un ritual. Esto último se consigue mediante la marca que la acción deja en la víctima y el reconocimiento por parte del perpetrador de haber triunfado con dichos actos (I995: 33-34).

El hecho de mantener a miles de personas recluidas en campos de concentración ya se puede considerar, según la definición de Foucault, una tortura. Igualmente, dentro de estos se llevan a cabo castigos adicionales que también pueden ser definidos como torturas. Por ejemplo, Neus Català cuenta que una noche despertaron a todas las mujeres y las hicieron salir al centro del campo donde había un caballete colocado. Las SS llamaron una por una a Simone, Hélène y Mimí, tres compañeras suyas, para darles veinticinco bastonazos estando apoyadas al caballete y con la ropa interior bajada. Neus menciona que tuvo el impulso de cerrar los ojos y no mirar, pero sabía que si lo hacía le pegarían a ella también. Continúa narrando que las SS recogieron a las tres mujeres del suelo y, con un gesto de adiós con la mano y una sonrisa, se las llevaron a rastras. Más tarde, las mismas SS irrumpieron en el bloque donde estaba Neus y gritaron en alemán a las mujeres que allí se encontraban que habían colgado a sus compañeras en Flossenbürg: "las han clavado por la garganta de un gancho de carnicero y las han dejado agonizar" (Martí, 20I2: 203), les tradujo una compañera.

Las torturas, además, arguye Foucault, son un método de revelación de la verdad y de demostración del poder; ambos motivos representados en la novela de Carme Martí. Neus relata que, cuando los nazis la detuvieron en su casa de Francia, la llevaron a la prefectura de Périgueux y allí, en un cuarto, la sentaron en una silla, le ataron las manos a la espalda, le pusieron una pistola en cada sien, una metralleta en la espalda y jugaron con el mecanismo de seguridad durante horas (2012: I04, I05). Además, aunque en este momento no menciona que le pegan, lo cierto es que la historia comienza haciendo referencia a este mismo episodio y Neus cuenta que "me desaté el pañuelo que me sostenía la mandíbula, que me habían fisurado durante el interrogatorio de hacía unos días" (20I2: 23). El objetivo de esta serie de actos era la confesión sobre los maquis que descubrieron en su casa el día de su detención. El hecho de que Neus no dijera nada durante el interrogatorio y, por ende, los 
policías no alcanzaran su propósito, no significa que estos dejen de ser considerados actos de tortura.

En cuanto al objetivo de demostrar poder, la novela está repleta de ejemplos de este tipo, pues la relación víctima-perpetrador se basa en una demostración continua de la jerarquización de los roles. Es importante mencionar también que la mayoría de estas acciones se cometían en el centro del campo de concentración, en la misma plaza donde pasaban horas para el recuento. La función de los castigos públicos no es tanto restablecer el equilibrio de la justicia, sino poner de nuevo en evidencia la disimetría existente entre quien ha violado una norma y quien se encarga de hacerla cumplir (Foucault, I995: 48-49).

\section{Conclusión}

El concepto de perpetrador está lleno de subjetividad, tanto de la persona sobre la que recae este concepto como de quien lo impone. Como se ha podido comprobar en la primera mitad de este estudio, resulta complejo establecer un perfil criminológico de los perpetradores. Se ha visto que hubo individuos que por su trabajo, por ejemplo, eran etiquetados como perpetradores $y$, sin embargo, de sus actos se desprendía una actitud completamente distinta. No obstante, este concepto sigue caracterizándose por sus límites poco definidos, que se vuelven incluso más complejos en eventos transnacionales y/o que perduran en el tiempo, como el que encuadra este artículo.

Lo cierto es que, siguiendo la teoría de Foucault, hay una serie de acciones que son propias de estas contrafiguras narrativas. De este modo, se puede concluir que son las acciones las que definen a los perpetradores y no al contrario, alejándonos así de la tendencia a definir estas figuras desde una contraposición con las víctimas. Este argumento lleva a comprender la razón por la que no se ha podido definir un perfil criminológico único y se encuentra, sin embargo, un amplio abanico de posibilidades: hombres, mujeres, adultos, niños, soldados, ciudadanos de a pie, testigos, etcétera. En otras palabras, se puede aseverar un continuo de la perpetración que comienza en las figuras normativas más tradicionales y que se disemina por el resto de la sociedad a través de su adoctrinamiento, la esencia antisemita y el hecho de que la ideología se apodere de sus vidas, tal como se ha mostrado en el segundo apartado de este artículo. 
Desde nuestra contemporaneidad cuesta comprender que el objetivo de los campos de concentración, junto con las acciones llevadas a cabo dentro de estos, fuera separar a los grupos considerados asociales del resto de ciudadanos para disciplinarlos. No obstante, alejándonos de cualquier planteamiento ético, estos lugares fueron construidos siguiendo unos patrones de maximización disciplinar exitosos. Tanto el encierro, como el control de la actividad de los presos y los castigos que se les infligían sirvieron para que los perpetradores tuvieran el control de sus cuerpos. Esta jerarquización entre víctimas y victimarios, ejercida a través de las torturas con el objetivo de demostrar su poder, la sufrieron un incontable número de hombres y mujeres: once millones de personas fueron asesinadas en los campos de concentración europeos y a casi cien mil, entre las que se incluye Neus Català, solo les salvó el fin de la Segunda Guerra Mundial.

\section{Bibliografía}

Assmann, Aleida \& Conrad, Sebastian. 2010. Memory in a Global Age: Discourses, Practices and Trajectories. Hampshire: Palgrave Macmillan.

Baum, Steven K. 2008. The Psychology of Genocide: Perpetrators, Bystanders, Rescuers. Cambridge: Cambridge UP.

Cuervo Álvarez, Benedicto. 20I7. Los campos de concentración. Historia Digital I7(30): I86-230.

De Grand, Alexander. 2000. Italian Fascism: Its Origins and Development. Lincoln: Nebraska UP.

De Juan Espinosa, Manuel \& García Rodríguez, Luis Francisco. 2004. Nuestra personalidad: en qué y por qué somos diferentes. Madrid: Editorial Biblioteca Nueva.

DeLeeuw, Joseph Gregory \& Pridemore, William Alex. 20I8. The Threat from Within: A Conjunctive Analysis of Domestic Terrorism Incidents in the United States and United Kingdom. Perspectives on Terrorism I2(4): 26-54.

Farrington, David. 2005. Childhood Origins of Antisocial Behavior. Clinical Psychology a Psychotherapy I2(3): I77-I90. doi: https://doi.org/I0.I002/cpp.448

Foucault, Michel. I995. Discipline \& Punish: The Birth of the Prison. Nueva York: Second Vintage Books Edition.

Freud, Sigmund. 1922. Group Psychology and the Analysis of the Ego. Viena: The International Psycho-Analytical Press.

Goeschel, Christian. 20I8. Mussolini and Hitler: The Forging of the Fascist Alliance. New Haven: Yale UP.

Goldhagen, Daniel Jonah. I997. Hitler's Willing Executioners. Ordinary Germans and the Holocaust. Nueva York: Random House. 
Herrmann, Gina. 2020. Spanish and Catalan Women in Ravensbrück. En Brenneis, Sara J. \& Herrmann, Gina (ed.) Spain, the Second World War, and the Holocaust: History and Representation. Toronto: University of Toronto P, 237-257.

Juaristi Linacero, Jon. 2009. Holocausto y terrorismo. Cuadernos de Pensamiento político 23: 55-66.

Lemkin, Raphael. I946. Genocide. The American Scholar I5(2): 227-230.

Lewy, Guenter. 20I7. Perpetrators: The World of the Holocaust Killers. Nueva York: Oxford UP.

Manzanero, Antonio L. \& Álvarez, Miguel Ángel. 20I5. La memoria humana: Aportaciones desde la neurociencia cognitiva. Madrid: Ediciones Pirámide.

Martí, Carme. [20I2] 2019. La paloma de Ravensbrück. Barcelona: Roca Editorial.

Megargee, Geoffrey P. \& Wiesel, Elie. 2009. The United States Holocaust Memorial Museum Encyclopedia of Camps and Ghettos, 1933-1945. Bloomington: Indiana UP.

Mohamed, Saira. 2015. Of Monsters and Men: Perpetrator Trauma and Mass Atrocity. Columbia Law Review II5(5): II57-I2I6.

Paxton, Robert O. 2005. The Anatomy of Fascism. Nueva York: First Vintage Books Edition.

Powell, Christopher. 20Ir. Barbaric Civilization: A Critical Sociology of Genocide. Montreal: McGill-Queen's UP.

Schmidt, Sibylle. 20I7. Perpetrators' Knowledge: What and How can We Learn from Perpetrator Testimony? Journal of Perpetrator Research, I(I): 85-104. doi: http:// doi.org/I0.21039/jpr.viir.38 